\begin{tabular}{l|l|l|l} 
cento e quatro & Sinais de cena 9. 2008 & Leituras & Ana Campos
\end{tabular}

\title{
0 teatro é uma arte política
}

\section{Ana Campos}

\author{
Juan Mayorga, Hamelin, tradução de \\ António Gonçalves, Lisboa, Artistas \\ Unidos/Cotovia, Livrinhos de Teatro, \\ n. ${ }^{\circ} 20,2007,71 \mathrm{pp}$.
}

Quando o que nos rodeia não é pacifico, quando a realidade nos incomoda, devemos agir. E o teatro é a forma artística por excelência de intervenção na cidade. É esta a pedra de toque da obra de Juan Mayorga (n. 1965) como o próprio afirmou num ensaio intitulado "El teatro es un arte político", onde expressou a sua crítica implacável à participação da Espanha na invasão do Iraque, sob o governo de José Maria Aznar, e a sua repulsa face ao discurso político, a seu ver, imperialista e prepotente com que os paises invasores procuravam sufocar as consciências.

Juan Mayorga nasceu em Madrid, licenciou-se em Filosofia e Matemática tendo apresentado uma tese de doutoramento sobre A filosofia da história em Walter Benjamin onde se debruçava não só sobre a obra deste autor, mas também sobre autores como Ernst Jünger, Georges Sorel, Donoso Cortés, Carl Schmitt e Franz Kafka. É professor de Dramaturgia e Filosofia na Real Escuela Superior de Arte Dramático de Madrid, é também um dos membros do grupo de investigação O judaísmo: Uma tradição esquecida na Europa e membro do conselho de redacção da revista Primer acto. É autor de diversas obras filosóficas bem como de teatro, sendo conhecido em Portugal pelas peças 0 caminho do céu, 0 jardim queimado e Animais nocturnos, também publicados na colecção Livrinhos de teatro, n. ${ }^{\circ}$ 12, e ainda pelas peças Cartas de amor a Stalin, Campo das Letras, 2002, e o Tradutor de Blumemberg, Revista dos Artistas Unidos, n. ${ }^{\circ}$ 10. A sua obra dramática está traduzida em diversas línguas, como o árabe, o francês, o romeno, o servo-croata, entre outras, e muitos dos seus textos foram já encenados em diversos paises europeus e latino-americanos. Em 2007 foi galardoado com o Prémio Nacional de Teatro atribuído pelo Ministério da Cultura de Espanha.

Em Hamelin (2005), de novo o autor se levanta para interpelar directamente a cidade. 0 que acontece enquanto a cidade dorme? Esta é a pergunta a que se propõe responder num texto que, antes de mais, fala da linguagem, do que ela permite construir e das limitações que nos impõe. Utilizada nesta obra de forma quase corpórea, a linguagem torneia as figuras, define o espaço, permite a percepção da passagem do tempo. $E_{1}$ como linguagem

Ana Campos implica comunicação, o leitor/espectador é convocado é investigadora do Centro de Estudos de Teatro e professora do ensino secundário. desta forma a tomar uma posição activa na construção da cena. Ecoa assim, como vemos, no texto o conceito de linguagem mágica de Walter Benjamin, de acordo com o qual, contar é fazer acontecer.

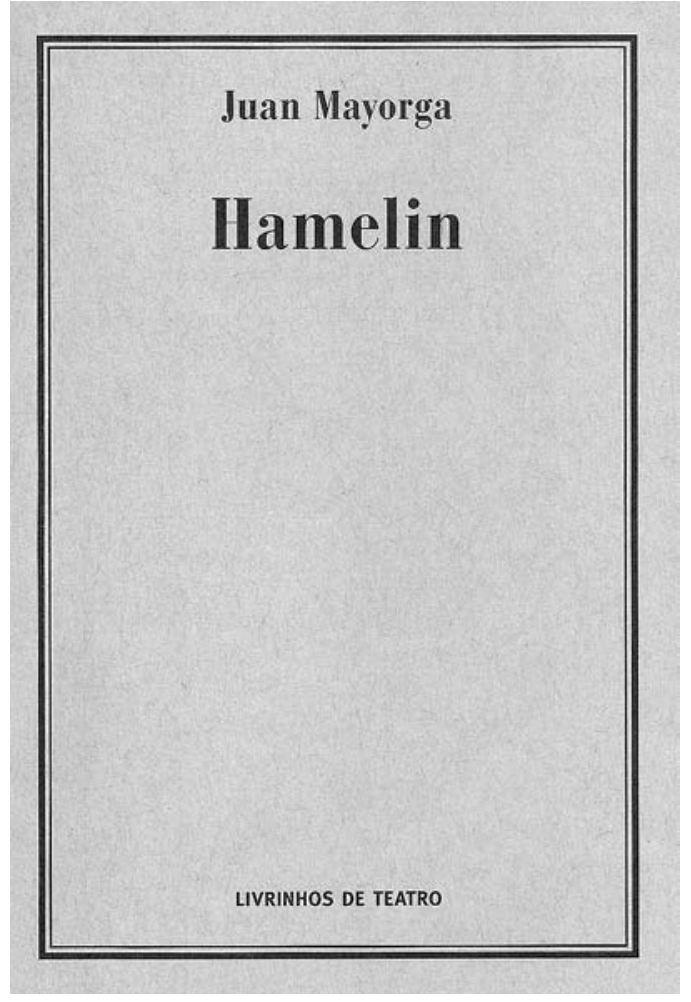

A importância da linguagem é ressaltada pela desconstrução do teatro assumida no texto através de um Comentador/personagem que interpela o público, que tece considerações sobre a cena e a sua construção, que narra acontecimentos, que convoca, por último, a crítica para dentro do próprio texto. Crítica que o autor entende ser uma peça fundamental na criação: "Sem crítica, a cultura prepara a barbárie. Ela mesma é barbárie", afirmou no ensaio "Cultura global y barbárie global".

Hamelin procura ser uma forma de criar memória e consciência. Rejeitando assumidamente o "choque" procurado pela imprensa, o texto retrabalha a realidade da pedofilia envolvendo figuras públicas sem que nunca esta palavra, já tão vulgarizada pelos media, seja proferida. Escândalos como o da Casa Pia ou outro semelhante ocorrido em Sevilha, desmantelamento de redes pedófilas que actuam pela Internet, por mms ou sms, envolvimentos de 1500 padres católicos nos EUA em tais práticas, a existência de um partido pedófilo legalmente constituído na Holanda, a difusão da cultura dos boylovers fazem parte de um conhecimento que partilhamos diariamente com o autor. Mas que, ao contrário do que procura a imprensa - que aliás surge como personagem colectiva, no texto definida como devoradora insaciável de 


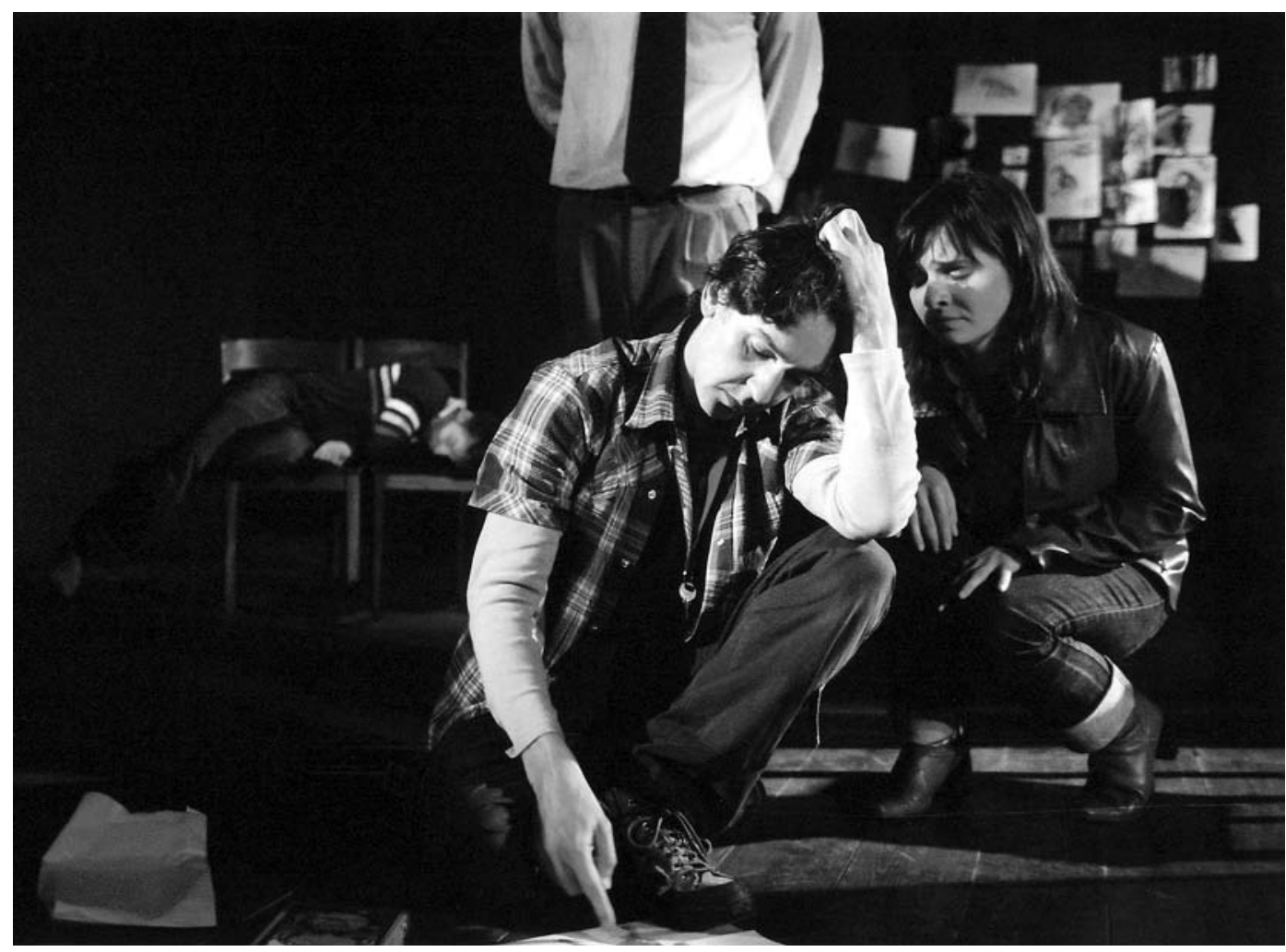

escândalos, emissora de condenações sem julgamento e produtora prolifera de má literatura - em Hamelin procurase fixar o problema de forma consciente e crítica.

Embora traçadas a grossas pinceladas, apenas na medida em que servem a fábula, as personagens deste texto assentam numa construção psicológica bastante bem fundamentada. Zé Maria, a criança abusada, após confessar o crime de que foi vítima, remete-se ao silêncio, no que o autor procura contrapor à mestria do uso da linguagem pelas personagens detentoras de poder (Rivas, o pedófilo, Monteiro, o juiz e Raquel, a psicóloga). Este silêncio é coerente com a interiorização da culpa do criminoso pela vítima - comum nestes casos -, e com o destruir das referências até aí tidas como aceitáveis pela personagem. Tal como é coerente, e assustadoramente familiar, a respeitabilidade do líder social, Rivas, no bairro onde encontrava as suas vitimas, cujo assédio começava com uma boleia para a missa, bem como o seu refúgio na religião depois de preso, e o seu afecto - verdadeiramente sentido mas pervertido - pela criança. Acreditamos facilmente também na familia desestruturada de Zé Maria - com os seus cinco irmãos e mais outro a chegar, da sua irmã / mãe adolescente e do pai alcoólico -, e na prontidão com que a familia ignorou os crimes sexuais perpetrados contra dois dos seus filhos em troca do pouco dinheiro com que se iam governando e da ilusão de que desse modo estavam a permitir que, pelo menos, um deles saisse do bairro e tivesse uma vida melhor.

A inquietação começa quando procuramos relacionar esta história com o conto de Hamelin, que dá nome à obra e é uma presença constante no texto. 0 que acontece enquanto a cidade dorme? A resposta é assustadora. Os ratos atacam as crianças. E esses ratos chamam-se possivelmente abandono, negligência, maus tratos físicos e psicológicos, abuso emocional, exposição a modelos comportamentais desviantes, e muitos outros, e também aqui existe um flautista, quase sempre um conhecido que canta a doce melodia do afecto e da protecção, mas que, como paga, rouba a infância de alguém para sempre.

A fragilidade da criança no conturbado mundo contemporâneo surge no texto a dois niveis: é a história de Zé Maria, mas também de Jaime, o filho de Monteiro, abandonado pelo pai que não sabe como falarIhe, que talvez nunca the conte a história de Hamelin, o menino rico que a psicóloga não consegue ajudar, nem a escola, nem a mãe, nem o pai, o menino rico que se revolta através da violência, que está livre dos perigos do bairro problemático mas a quem ninguém consegue dar a mão.

Esta obra detém-se sobre o lado mais escuro da realidade, interrogando-o, interrogando-nos. Os símbolos do discurso apologético do progresso, o museu de arte moderna, o novo estádio, o auditório, são a luz que nos impede de ver a cidade escondida que esta história procura trazer à cena. Se é incontornável que o autor consegue com este texto não nos fazer esquecer, também é legítimo perguntar que nova luz sobre a realidade da pedofilia nos traz para além do discurso que domina a opinião pública. A peça inquieta-nos, culpabiliza-nos, faz-nos reflectir enquanto pais e cidadãos, mas é talvez demasiadamente comprometida ideologicamente. 0 texto sustém uma tese: a ideia de que as vítimas do ritmo vertiginoso do progresso e das suas consequências sociais são as crianças, que ficam abandonadas, negligenciadas, à mercê de qualquer música encantatória, o que é, a meu ver, uma abordagem social e politicamente comprometida do problema mais complexo da pedofilia, das perversões afectivas e dos jogos de poder a ela subjacentes.

Hamelin estreou em Madrid, no Teatro da Abadia, a 12 de Maio de 2005 numa encenação de Andrés Lima e, em Portugal, a 12 de Abril de 2007, no Convento das Mónicas, numa notável produção dos Artistas Unidos. 